\title{
Asylum architecture
}

\section{Susan Floate, Librarian, Royal College of Psychiatrists, 17 Belgrave Square, London SW 1X 8PG}

The College library is continuing with its project to photograph some of the large old psychiatric hospitals. With the planned closure and possible demolition of many of these institutions it seems worthwhile to record the architecture of the buildings, although inevitably most have been extended, renovated or dissected over the years. Initially hospitals in the vicinity of London are being photographed but we hope to include establishments throughout the country and would be pleased to receive photographs of any architecturally interesting psychiatric hospitals to add to our collection. (Photographs on this spread by Mr C. Priest/MAGPIE Reprographics.)

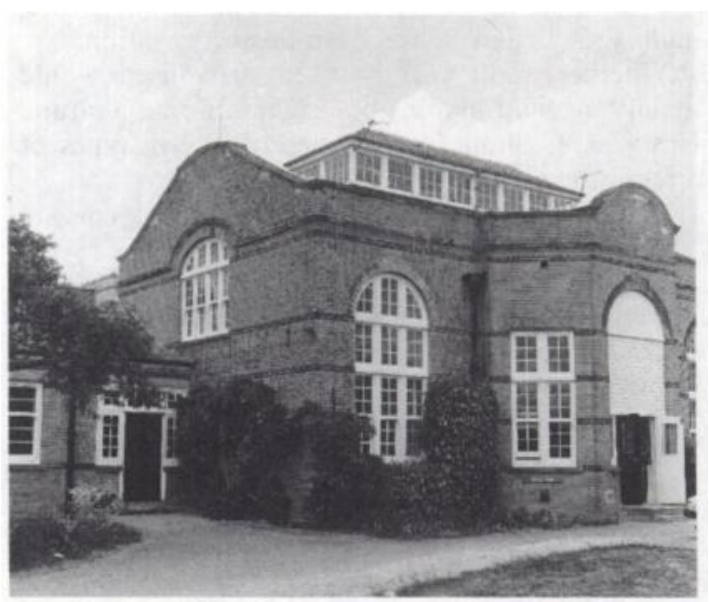

Napsbury. Built in 1905 to accommodate 1150 patients, Napsbury was described by the Commissioners in Lunacy as "somewhat expensively equipped".

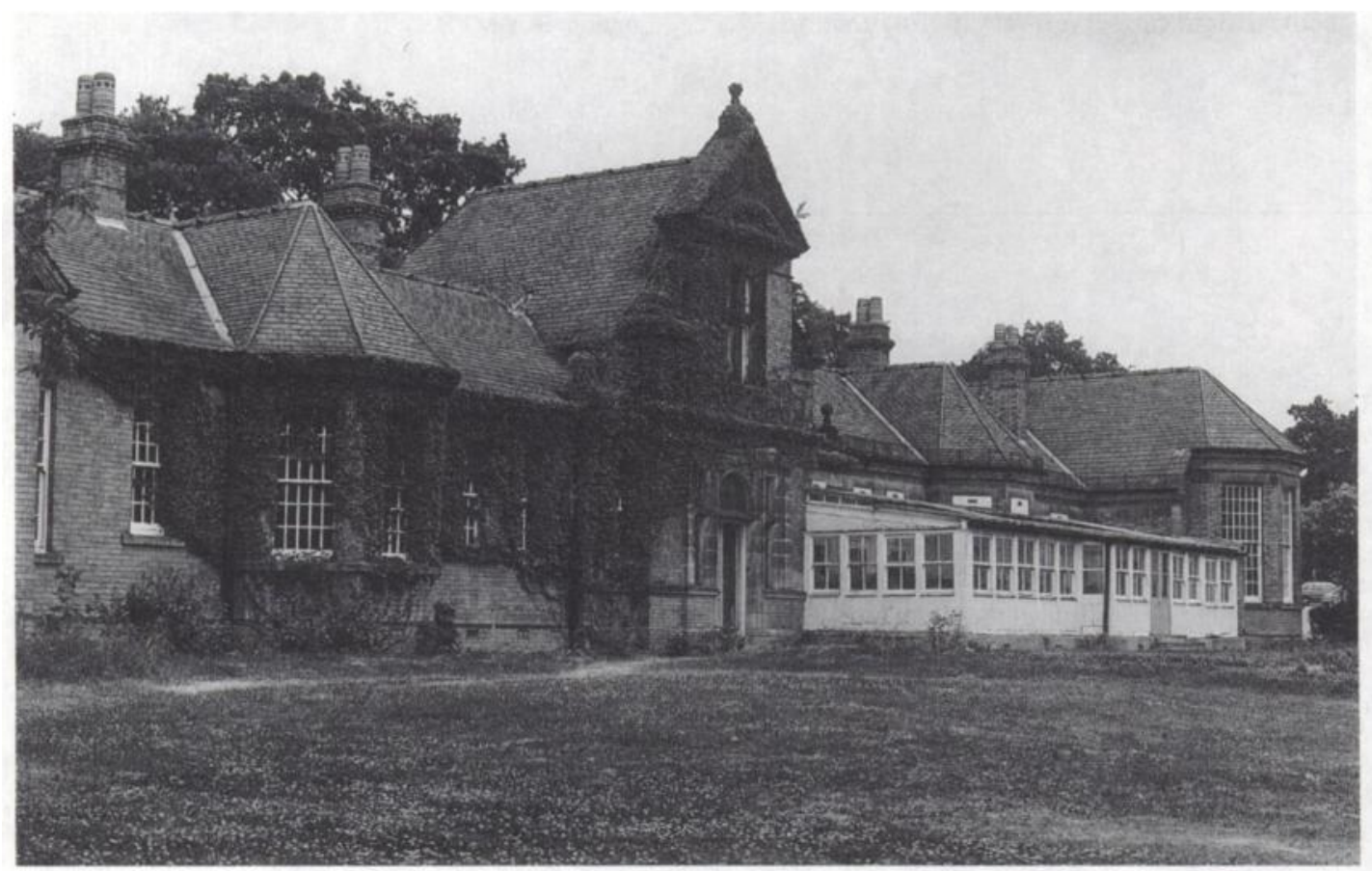

Claybury. In 1887 a property of 260 acres was acquired for the building of a new asylum, at Woodford in Essex. Construction began in 1889 and the first of the 2000 patients was admitted to Claybury in 1893. 


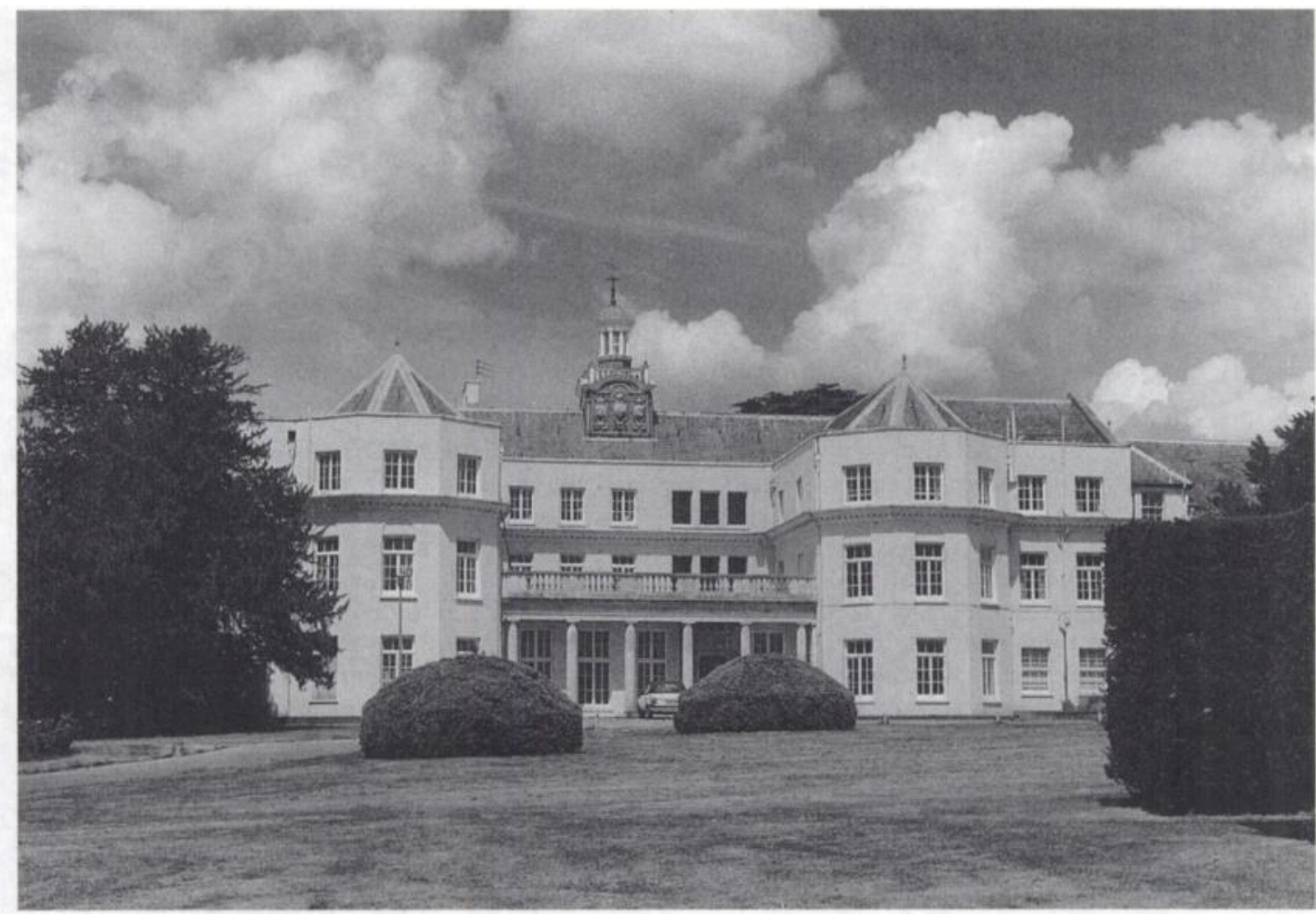

Shenley. Opened by George V in May 1934, Shenley was the last of the 2000-bed asylums to be built.

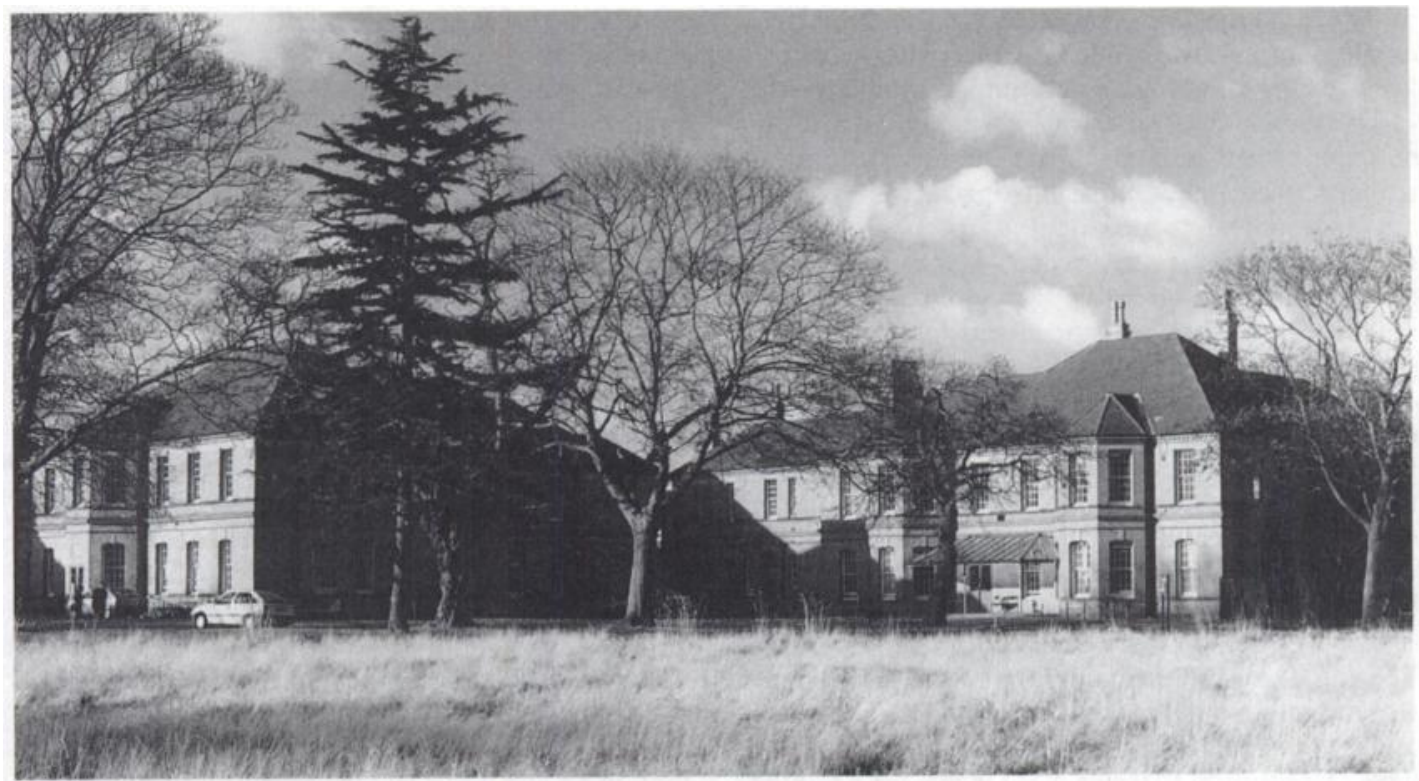

Hill End. Hertfordshire County Asylum was completed in 1902 and initially had accommodation for 626 patients. 